CASE REPORT

\title{
Clinically Confirmed Congenital Rubella Syndrome: The Role of Echocardiography
}

\author{
Demeke Mekonnen*
}

\author{
OPEN ACCESS \\ Citation: Demeke Mekonnen. Clinically \\ Confirmed Congenital Rubella \\ Syndrome: The Role of \\ Echocardiography. Ethiop J Health Sci \\ 2017;27(1):197. \\ http://dx.doi.org/10.4314/ejhs.v27i2.13 \\ Received: October 24, 2016 \\ Accepted: October 30, 2016 \\ Published: March 1, 2017 \\ Copyright: () 2015 Demeke, M. This is \\ an open access article distributed under \\ the terms of the Creative Commons \\ Attribution License, which permits \\ unrestricted use, distribution, and \\ reproduction in any medium, provided the \\ original author and source are credited. \\ Funding: Nil \\ Competing Interests: The authors \\ declare that this manuscript was approved \\ by all authors in its form and that no \\ competing interest exists. \\ Affiliation and Correspondence: \\ ${ }^{1}$ Wolfson Medical Center, Israel; \\ Jimma University, Ethiopia \\ Email: demekemm@yahoo.com
}

\begin{abstract}
BACKGROUND: Congenital rubella syndrome (CRS) affects thousands of children in the developing world because rubella vaccination is not routinely available in most of these countries. Among its many manifestations, congenital heart disease is life threatening.

CASE DETAILS: A 9-month-old infant presented with whitish lesions over her left eye. She was evaluated with echocardiography that revealed peripheral pulmonary stenosis and patent ductus arteriosus. She had severe acute malnutrition and clinically confirmed congenital rubella syndrome (CRS). There was no available serologic test to confirm the diagnosis.

CONCLUSION: This case was presented to demonstrate typical dual features of CRS by echocardiography and to emphasize the benefit of vaccination to prevent deleterious complications from congenital rubella syndrome.

KEYWORDS: Congenital rubella syndrome, PDA, peripheral pulmonary stenosis
\end{abstract}

\section{INTRODUCTION}

The name rubella is derived from a Latin term meaning "little red". Rubella is generally a benign, communicable and exanthematous disease. It is caused by rubella virus, which is a member of the Rubivirus genus of the family Togaviridae. Rubella is characterized by a mild, maculopapular rash. However, up to $50 \%$ of rubella infections are subclinical, sometimes misdiagnosed as measles or scarlet fever (1).

In 2014, 141 CRS cases were reported from 114 countries mostly from Southeast Asia $(n=86 / 141)$. Therefore, the authors felt that the reporting may be inconsistent, as it is estimated that each developing country experiences an incidence of 100,000 cases per year alone (2).

Rubella virus is generally acquired by airborne distribution and enters the maternal respiratory tract (1). It is often so difficult to verify rubella exposure during pregnancy in postpartum mothers who may have actually had such a mild,

subclinical infection that it remained

The fetus acquires rubella through the course of pregnancy. The clinical significance depends on

DOI: http://dx.doi.org/10.4314/ejhs.v27i2.13 
the time of the mother's acquisition of the virus. If maternal infection happens to be in the first trimester, the risk of rubella-associated defects is greatly increased. According to Pumper and Yamashiroya, between $50 \%$ and $80 \%$ of fetuses exposed to maternal rubella virus become infected prior to the $8^{\text {th }}$ weeks of gestation. Infection of the fetus is fairly uncommon, during the $3^{\text {rd }}$ trimester which is $6 \%-10 \%$ (3). The eyes, the ears, the heart, the central nervous system and the brain appear to be especially susceptible to rubellaassociated damage (4).

When maternal rubella is present, the virus spreads through the placenta and in to the fetus. In the placenta, the chorionic tissues are the most affected. They experience necrosis of the epithelium and fragmentation of the small blood vessels. The virus may spread to fetal tissues via infected emboli or direct damage to the small fetal blood vessels. The virus resides in the cell's nucleus as clones or group of cells, as demonstrated by fluorescent antibody technique (5).

Severe rubella virus infection, acquired in utero early in pregnancy, is named as Congenital Rubella Syndrome (CRS). It refers to variable constellations of birth defects (for example, hearing impairment, congenital heart defects, cataracts or congenital glaucoma, pigmentary retinopathy, etc). WHO developed clinical criteria to classify CRS as either Suspected CRS case, Clinically Confirmed CRS case, Laboratory Confirmed CRS Case or Congenital Rubella Infection (CRI) (6).

Previous studies focused on the CRS triads: hearing impairments, cataracts and congenital heart disease (7). Later, the distinguishing CRS features expanded to include low birth weight and delayed neonatal growth, thrombocytopenic purpura, transient bone lesions, anemia, hepatitis, microcephaly, psychomotor retardation and other disorders $(5,8,9)$.

Rubella virus antigens were detected in myocardial fibroblasts of two patients, although they did not have histological signs of myocarditis or viral antigens in their cardiac myocytes (10). Additional evidence of the presence of viral antigens in adventitial fibroblasts of large blood vessels helps explain the possible mechanisms for congenital cardiovascular malformations (patent ductus arteriosus and branch pulmonary artery stenosis) in CRS patients. This evidence potentially excludes the prior thoughts about the cytolytic injury of cardiac myocytes and more likely suggests a disturbance of the normal development of the cardiovascular system through cardiac fibroblasts infection. These fibroblasts normally form structural scaffolding for the attachment of cardiac cell types during development, express growth factors and cytokines, and regulate proliferation of embryonic cardiomyocytes (11).

In summary, although the mechanisms by which rubella virus causes fetal damage are poorly understood; the defects observed are likely secondary to vasculitis resulting in tissue necrosis without inflammation. Another possible mechanism is direct viral damage of infected cells. CRS is one of the vaccine preventable diseases which could result in extended level of teratogenicity when left unnoticed during early pregnancy.

\section{CASE REPORT}

We are presenting a 9-month-old female infant who presented to our clinic with a whitish lesion of the left eye since birth. Our assessment and investigations are presented here in detail with analysis of the case following it.

On history, she was born at term in a health center. The pregnancy and delivery were uneventful. The mother did not remember the birth weight, but claimed that the child was smaller compared to her other children. She had three older children who were relatively healthy.

She was exclusively breast feed for only three months and started on half strength cow's milk and gruel made of mixed cereals. She had intermittent cough for a long period, which was treated locally with antibiotics. Although the cough decreased with antibiotics, it recurred frequently.

She did not have interruption of feeding, excessive sweating or body swelling. She could not sit, crawl or stand without support. She could not say mama or papa. She was vaccinated for her

DOI: http://dx.doi.org/10.4314/ejhs.v27i2.13 
age according to the national expanded program of immunization.

The mother had antenatal care follow-up and was told that there were no concerns. She was screened for available blood test, but not for rubella. There was no genetic or fetal echocardiography screening.

On clinical examination, she had no cardiorespiratory distress with vital signs of heart rate 130 beats per minute which was full in volume and bounding, and a respiratory rate 48 breaths per minute which was regular and shallow. She was severely wasted and stunted. She had microcephaly. She had a whitish lesion over the left eye but there no discharge or swelling around it. She did not follow objects during evaluation.

Her chest was clear and resonant, and no abnormality was detected. On cardiovascular examination, the precordium was silent with the apical beat shifting leftward and inferiorly at the $5^{\text {th }}$ intercostal space lateral to the midclavicular line. Normal heart sounds with three out of six machinery murmur at the upper left sternal border and at the back were heard. The rest of the systemic examination showed no further clinically significant abnormalities. Ophthalmologic evaluation revealed congenital cataract of the left eye.

No abnormality was found on the routine blood (complete blood count, peripheral blood smear), urine and stool tests. There was no available serologic study for rubella. A chest x-ray showed symmetrical pulmonary vascular markings and increased cardiothoracic ratio of $62.5 \%$ signaling cardiomegaly.

Echocardiography revealed normal segmental anatomy with normal systemic and pulmonary venous connections. Both The interatrial and inerventricular septa were intact. Atrioventricular valves were structurally normal with good diastolic flow across. There was good biventricular function with mild enlargement of the left ventricle. Both aortic and pulmonic valves were structurally normal with trivial pulmonary valve regurgitation. Main Pulmonary Artery and Left Pulmonary Artery were good sized, $10.4 \mathrm{~mm}$ (Z-score 0.62) and 5.3mm (Z-score 0.21) and with normal flow across respectively. The Right Pulmonary Artery was stenosed 3.6mm (Z-score -
2.71) with a pressure gradient across being $23 \mathrm{mmHg}$. Coronary arteries were normal in origin and proximal part. Left aortic arch with no coarctation and pulsatile flow across the descending aorta with mild flow reversal was seen. There was a Small sized Patent Ductus Arteriosus (PDA) (2.6mm) with a left to right flow across and pressure gradient across was $30 \mathrm{mmHg}$. There was no pericardial or pleural effusion identified (Figures 1, Figure 2, Table 1).

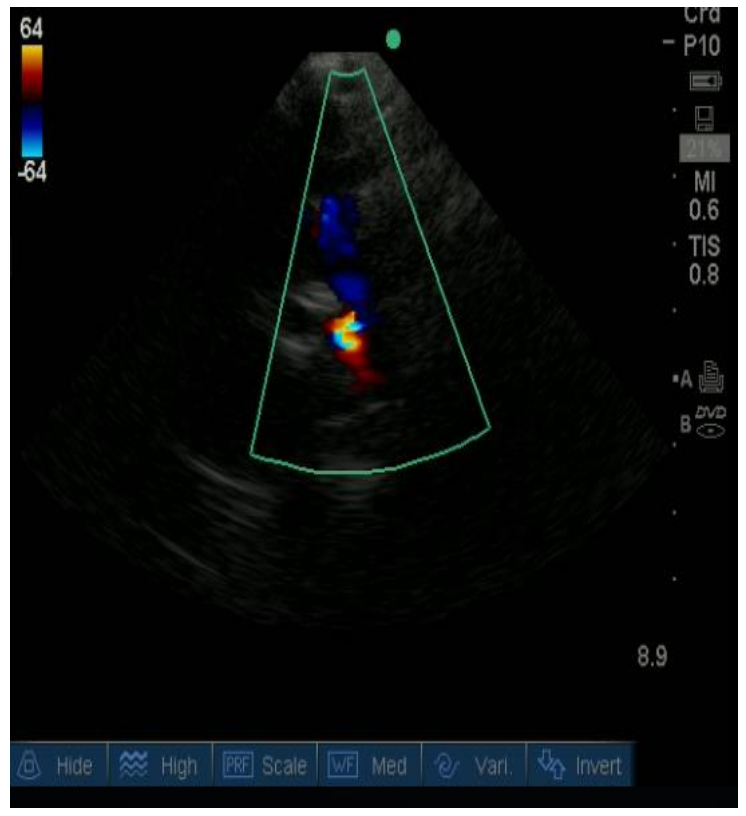

Figure 1: Echocardiographic 2D colour image showing PDA flow, Jimma 2016

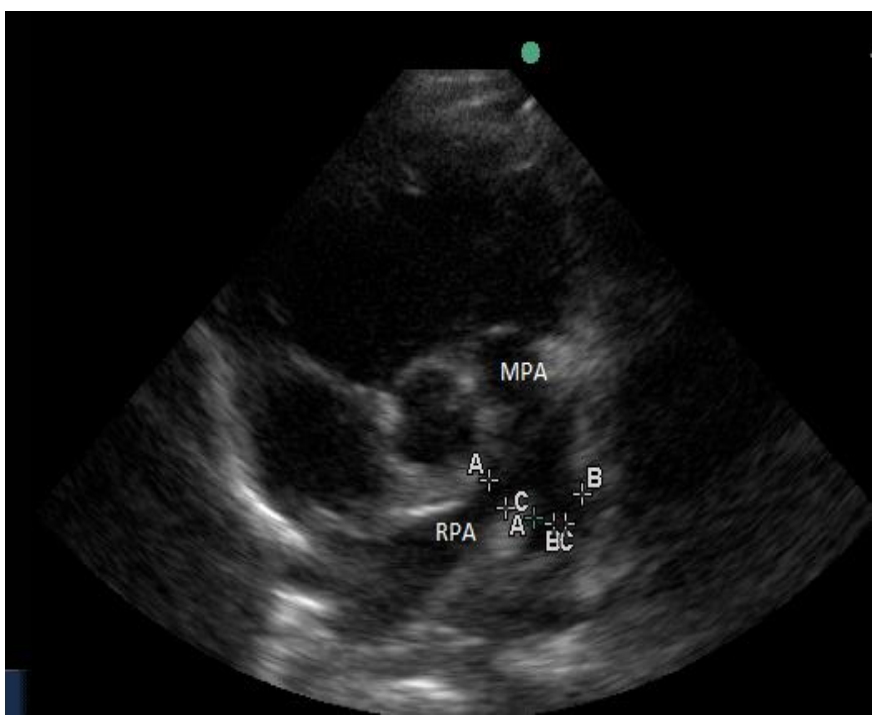


Figure 2: Echocardiographic 2D image showing

the sizes of RPA, LPA, and PDA, Jimma

Table 1: z score values for the main pulmonary artery and its branches, Jimma 2016

\begin{tabular}{llll}
\hline Pulmonary Artery & Size & $*$ Z-score $(33)$ & PG across \\
\hline RPA & $3.6 \mathrm{~mm}$ & -2.71 & $23 \mathrm{mmHg}$ \\
LPA & $5.3 \mathrm{~mm}$ & 0.21 & $6 \mathrm{mmHg}$ \\
MPA & $10.4 \mathrm{~mm}$ & 0.62 & $4 \mathrm{mmHg}$ \\
PDA & $2.6 \mathrm{~mm}$ & & $30 \mathrm{mmHg}$ \\
\hline
\end{tabular}

* Review the reference for the use of the Z-score values and how it was done (12)

The patient was admitted with the assessment of severe acute malnutrition (non edematous) + clinically confirmed CRS (left eye congenital cataract + Congenital heart disease (PDA and Proximal Right Pulmonary Artery stenosis) + microcephaly).

Treatment was started for severe acute malnutrition according to the national guideline for the management of malnutrition. The patient was put in follow-up for further study and management of the congenital heart disease since there was no need for intervention for closure of PDA. Such children can be followed as they are good candidates for percutaneous ductal closure and balloon dilatation of PPS. If they develop heart failure, medical treatment can be introduced. If medical treatment of congestive heart failure fails, the patients will be referred early for closure of the PDA (13).

\section{DISCUSSION}

The embryologic development of the heart is at the same time as the inner ear and the lens. Therefore, damage to the ears and eyes is often accompanied by a variety of heart defects (14). Thus, infection by rubella at this gestational age results in combined infection to those organs.

Depending on the timing of organogenesis, organs involved in the CRS are variable. Infection on about the $36^{\text {th }}$ day of gestation leads to cataracts, heart defects on the $46^{\text {th }}$ and to defects of the inner ear from the $62^{\text {nd }}$ day to the end of $16^{\text {th }}$ gestational week. Infection in the first 1-6 weeks of gestation has a risk of $56 \%$ embryopathies, in the $7^{\text {th }}-9^{\text {th }}$ weeks to $25 \%$, in the $10^{\text {th }}-12^{\text {th }}$ weeks to $15 \%$, in the $13^{\text {th }}-16^{\text {th }}$ weeks to $6 \%-10 \%$, in the $17^{\text {th }}-21^{\text {st }}$ weeks to less than $5 \%$ and after 22 weeks of gestation to no embryopathies (15).
Multiple and unspecified congenital heart diseases may present in relation to CRS. They include, but are not limited to, patent ductus arteriosis, pulmonic stenosis, aortic stenosis, atrial septal defect and ventricular defect. A total of $32.5 \%$ of the cases had cardiac lesions of different types (7). O'Donnell gathered information on 88 individuals with CRS found that $32 \%$ had a heart condition. Patent Ductus Arteriosus, Atrial or Ventricular Septal Defects and Pulmonary Stenosis were the most common (16). Other studies had also demonstrated that heart disease was one of the leading problems identified in $50 \%$ of cases $(5,8)$.

Patent ductus arteriosus and branch pulmonary artery stenosis are the most common lesions (17). Other lesions, including pulmonary valvular stenosis, aortic valve stenosis, ventricular septal defect, tetralogy of Fallot and coarctation of the aorta have been also reported (17). Our case had also the typical features of CRS with peripheral pulmonary stenosis and patent ductus arteriosus.

The presence of PDA with left to right shunt can manifest with increased flow across the pulmonary artery by then disguises the Doppler study for measuring peripheral pulmonary stenosis. According to the study by Danilowitz et al (18), during cardiac catheterization, the reseasrchers were able to confirm only physiologic increment in flow rather than actual pulmonary stenosis. The study by Maroto et al (19) did not identify cases with combined PDA and peripheral pulmonary stenosis in the general population.

It was found from different studies that the presence of branch pulmonary artery stenosis during the early periods of premature babies was transient where complete resolution occurs in the first three months of life. This was not the case in

DOI: http://dx.doi.org/10.4314/ejhs.v27i2.13 
conditions with congenital rubella syndrome and Allagille syndrome associated peripheral stenosis where spontaneous recovery was not expected. There were studies which demonstrated development of pulmonary stenosis while they try to close PDA in premature babies using Indomethacine treatment (18-20).

In conclusion, the presence of cardiac manifestations in CRS is significant and can be diagnosed with echocardiography as it might not be symptomatic. What makes it typical in our case is the presentation of combined PDA and pulmonary stenosis which need special attention in the diagnosis and management of PDA. It is recommended that any infant who is suspected to have congenital rubella syndrome should undergo cardiac evaluation by echocardiography at presentation. Because it leads to progressive multi-organ deterioration, the clinician should remain vigilant of the potential health problems, and affected patients should be kept under close follow-up. Last, prevention by maintaining a vigorous approach of rubella immunizations remains the best strategy to eliminate all cases of CRS.

\section{ACKNOWLEDGEMENT}

I would like to acknowledge the contribution from Dr. Daniel Teklu, a pediatric resident in Jimma University, who had been clinically evaluating and following the infant. Great thanks to Dr. Tigist M. and pediatric department colleagues for their contribution in the process.

\section{REFERENCES}

1. Centers for Disease Control and Prevention. Epidemiology and Prevention of Vaccine Preventable Diseases, Rubella. Atkinson W, Hamborsky J, Wolfe S, eds. 12th ed., second printing. Washington DC: Public Health Foundation, 2012:275-290.

2. Grant G.B., Reef S.E., Dabbagh A., Gacic-Dobo M., Strebel P.M. Global progress toward rubella and congenital rubella syndrome control and elimination 2000-2014. MMWR Morb. Mortal. Wkly Rep. 2015; 64 (37):1052-1055.

3. Pumper R.W. and Yamashiroya H.M. Essentials of Medical Virology. W.B. Saunders. Philadelphia. 1975.
4. McInnes,J.M. and Treffry J.A. Deaf-Blind Infants and Children: A Developmental Guide. Open University Press. Toronto. 1982.

5. Desmond M.M. Medical Aspects of the Congenital Rubella Syndrome. Paper. Baylor College of Medicine, Houston, Texas Samuel P. Hayes Research Library, Perkins School for the Blind, Watertown, Mass. 1975.

6. WHO-recommended surveillance standard of rubella and congenital rubella syndrome:http://www.who.int/immunization/monit oring_surveillance/burden/vpd/surveillance_type/a ctive/rubella_standards/en/. Accessed on 02.07.2016.

7. Chess S. and Fernandez P. Impulsivity in rubella deaf children: A longitudinal study. American Annals of the Deaf. 1980; 125:505-509.

8. Cooper L. Rubella: Clinical manifestations and management. American Journal Dis Child. 1969; 118: 18.

9. Michaels R.H. and Kenny F.M. Postnatal Growth Retardation in Congenital Rubella. Paeditrics. 1969; 43: 251-259.

10. Lazar M, Ludmila Perelygina, Roosecelis Martines, et al. Immunolocalization and distribution of rubella antigen in fatal congenital rubella syndrome. EBioMedicine. 2016; 3:86-92.

11. Deb A., Ubil E. Cardiac fibroblast in development and wound healing. J. Mol. Cell. Cardiol. 2014; 70: 47-55.

12. Pettersen MD, Du W, Skeens ME, Humes RA. Regression equations for calculation of $\mathrm{z}$ scores of cardiac structures in a large cohort of healthy infants, children, and adolescents: an echocardiographic study. J Am Soc Echocardiogr. 2008 Aug; 21(8):922-934.

13. Chen Z, Chen L, Wu L. Transcatheter amplatzer occlusion and surgical closure of patent ductus arteriosus: comparison of effectiveness and costs in a low-income country. Pediatr Cardiol. 2009 Aug; 30(6):781-5.

14. Dijk J.van. Rubella Handicapped Children. Swets \& Zeitlinger B.V., Lisse (The Netherlands). 1982.

15. Burg G., Kunze J., Pongratz D., Scheurlen P.G., Schinzel A., Spranger J. (eds.) Die klinischen syndrome. Volume 1 and 2. 7th revised edition. Urban \& Schwarzenberg. München. 1990.

16. O'Donnell N. A Report on a Survey of Late Emerging Manifestations of Congenital Rubella Syndrome. Helen Keller National Center, New York. June 1991.

17. Oster ME, Riehle-Colarusso T, Correa A. An update on cardiovascular malformations in

DOI: http://dx.doi.org/10.4314/ejhs.v27i2.13 
congenital rubella syndrome. Birth Defects Res A Clin Mol Teratol. 2010; 88:1.

18. Danilowicz DA, Rudolph AM, Hoffman JI, Heymann M. Physiologic pressure differences between main and branch pulmonary arteries in infants. Circulation. 1972; 45:410-19.
19. R Arlettaza, N Archerb, A R Wilkinsonb. Closure of the ductus arteriosus: determinant factor in the appearance of transient peripheral pulmonary stenosis of the neonate. J Pediatr. 1991; 119: 9559.

20. Rodriguez RJ, Riggs TW. Physiologic peripheral pulmonic stenosis in infancy. Am J Cardiol. 1990; 66:1478-81. 